\title{
PENGARUH PANJANG ZONA GASIFIKASI BATUBARA BAWAH TANAH TERHADAP KOMPOSISI GAS HASIL (EFFECT OF ZONA LENGTH OF AN UNDERGROUND COAL GASIFICATION TO THE GAS PRODUCT COMPOSITION)
}

\author{
Harijanto Soetjijo * \\ Harijanto Soetjijo, Pengaruh Panjang Zona Gasifikasi Batubara Bawah Tanah Terhadap \\ Komposisi Gas Hasil (Effect of Zona Length of An Underground Coal Gasification to \\ The Gas Product Composition), RISET - Geologi dan Pertambangan Jilid 16 No.2 Tahun \\ 2006, hal. 49 - 60 gambar, 1 tabel.
}

\begin{abstract}
In laboratory, an underground coal gasification experiment has been conducted to examine the effect of different zone length of gasification to the composition of product gases. For that purpose two cylindris reactors which have different length are used. The length of first reactor is $80 \mathrm{~cm}$ and second reactor is $200 \mathrm{~cm}$; both reactors has same diameter of $30 \mathrm{~cm}$. The gasification is conducted for 24 hours with the input air volume to the reactor is arranged at 70 liter/minute. The composition of gas produces from the first reactor is as follows: $\mathrm{CO}_{2}=(11.6-14.4) \% ; \mathrm{C}_{\mathrm{n}} \mathrm{H}_{\mathrm{m}}=(0.0-0.4) \%$; $\mathrm{CO}=(1.2-6.8) \% ; \mathrm{O}_{2}=$ (3.2-7.2)\%; $\mathrm{H}_{2}=(0.8-3.2) \% ; \mathrm{C}_{3} \mathrm{H}_{8}=(0.0-0.9) \% ; \mathrm{CH}_{4}=(0.2-3.0) \%$. On the other hand, the second reactor produces gas with composition as follows: $\mathrm{CO}_{2}=(5.0-15.0) \% ; \mathrm{C}_{\mathrm{n}} \mathrm{H}_{\mathrm{m}}=$ $(0.0-0.3) \% ; \mathrm{CO}=(1.8-4.0) \% ; \mathrm{O}_{2}=(4.0-13.8) \% ; \mathrm{H}_{2}=(0.2-4.0) \% ; \mathrm{C}_{3} \mathrm{H}_{8}=(0.0-1.2) \% ; \mathrm{CH}_{4}$ $=(0.1-1.7) \%$. It is shown that the procentage of $\mathrm{CO}_{2} ; \mathrm{CO} ; \mathrm{H}_{2}$ and $\mathrm{CH}_{4}$ gas from the first reactor is higher than the second reactor. This result indicates that gasification reactions in the first reactor run better than the reactions occur in the second reactor. It is also supported by the calorific value of gas which is in the range of $(127-517) \mathrm{kcal} / \mathrm{m}^{3}$ for the gas from the first reactor compared with $(118-460) \mathrm{kcal} / \mathrm{m}^{3}$ for the gas from the second reactor. The different pattern of temperature $\mathrm{T} 1$ and $\mathrm{T} 2$ obtained from each reactor also supports this.
\end{abstract}

Sari: Eksperimen gasifikasi batubara bawah yanah telah disimulasikan dilaboratorium. Eksperimen dilakukan dengan tujuan untuk menyelidiki pengaruh perbedaan panjang zona gasifikasi terhadap komposisi gas hasil. Untuk tujuan itu dua buah reaktor yang berbentuk silinder dengan panjang yang berbeda dipergunakan. Panjang reaktor pertama adalah $80 \mathrm{~cm}$ dan reaktor kedua adalah $200 \mathrm{~cm}$; kedua reaktor mempunyai diameter yang sama yaitu $30 \mathrm{~cm}$. Gasifikasi dilakukan selama 24 jam dengan volume udara yang ditiupkan masuk kedalam reaktor diatur sebesar 70 liter per menit. Hasil percobaan menunjukkan bahwa komposisi gas-gas yang dihasilkan dari reaktor pertama adalah sebagai berikut: $\mathrm{CO}_{2}=(11,6-14,4) \% ; \mathrm{C}_{\mathrm{n}} \mathrm{H}_{\mathrm{m}}=(0,0-0,4) \%$; $\mathrm{CO}=(1,2-6,8) \% ; \mathrm{O}_{2}=(3,2-$ $7,2) \% ; \mathrm{H}_{2}=(0,8-3,2) \% ; \mathrm{C}_{3} \mathrm{H}_{8}=(0,0-0,9) \% ; \mathrm{CH}_{4}=(0,2-3,0) \%$. Dilain pihak, reaktor kedua menghasilkan gas dengan komposisi: $\mathrm{CO}_{2}=(5,0-15,0) \% ; \mathrm{C}_{\mathrm{n}} \mathrm{H}_{\mathrm{m}}=(0,0-0,3) \%$; $\mathrm{CO}$ $=(1,8-4,0) \% ; \mathrm{O}_{2}=(4,0-13,8) \% ; \mathrm{H}_{2}=(0,2-4,0) \% ; \mathrm{C}_{3} \mathrm{H}_{8}=(0,0-1,2) \% ; \mathrm{CH}_{4}=(0,1-1,7) \%$. Hasil ini memperlihatkan bahwa prosentase gas $\mathrm{CO}_{2} ; \mathrm{CO} ; \mathrm{H}_{2}$ dan $\mathrm{CH}_{4}$ dari reaktor pertama lebih tinggi dibandingkan dengan reaktor kedua. Hasil tersebut mengindikasikan bahwa reaksi-reaksi gasifikasi yang terjadi pada reaktor pertama berjalan lebih baik baik dibandingkan dengan reaksi yang terjadi pada reaktor kedua. Hal ini juga didukung oleh nilai kalori gas yaitu berada dalam kisaran antara(127-517) $\mathrm{kcal} / \mathrm{m}^{3}$ untuk gas yang dihasilkan dari reaktor pertama dibandingkan dengan (118-460) $\mathrm{kcal} / \mathrm{m}^{3}$ untuk gas yang berasal dari reaktor kedua. Perbedaan pola temperatur T1 dan T2 dari masing-masing reaktor juga mendukung hal tersebut. 


\section{PENDAHULUAN}

Gasifikasi adalah suatu proses kimiawi untuk mengubah suatu bahan bakar berbentuk solid atau cair menjadi berbentuk gas. Gasifikasi batubara bawah tanah adalah suatu proses gasifikasi batubara yang dilakukan ditempat dimana batubara itu berada tanpa menambang batubara itu terlebih dahulu. Gasifikasi ini merupakan suatu cara pemecahan yang lebih murah biayanya untuk memanfaatkan endapan batubara disuatu daerah yang mempunyai masalah yang berkaitan dengan lingkungan misalnya yang terletak didaerah hutan lindung. Tes skala besar dari gasifikasi batubara bawah tanah sampai saat ini masih giat dilakukan diberbagai negara baik di Eropa , Asia, Australia, Amerika (Armitage,M., Green, M.B., 2001). Proses gasifikasi batubara bawah tanah dimulai dengan cara melakukan pemboran untuk mencapai lapisan batubara dan melakukan suatu jalur penghubung/link dan diikuti dengan proses gasifikasi. Hal ini dilakukan dengan cara menginjeksi suatu oksidan (biasanya udara), menggasifikasi lapisan batubara dan mengambil produk gas yang dihasilkannya kepermukaan bumi melalui lubang-lubang bor yang dibuat dari permukaan sehingga dapat menghilangkan biaya penambangan dan reklamasi. Gas hasil tersebut dapat digunakan untuk pembangkit tenaga listrik, sumber panas untuk industri ataupun sebagai bahan baku kimiawi (chemical feedstock). Edgar, 1974 menyebutkan bahwa metoda gasifikasi batubara bawah tanah merupakan metoda yang paling ekonomis untuk merubah endapan batubara yang letaknya jauh didalam bumi menjadi gas meskipun aplikasi dari konsep ini untuk skala besar masih sulit dan memerlukan penelitian lanjutan.

Ada tiga grup parameter-parameter yang harus dipertimbangkan dalam pelaksanaan suatu proses gasifikasi batubara bawah tanah. Parameter pertama adalah parameter geologi seperti tebal lapisan, jenis lapisan penutup, lapisan dasar dll. Grup parameter kedua adalah parameter-parameter yang berhubungan dengan sifat batubara seperti kandungan air, kandungan abu, sifat pengembangan dsb-nya. Grup ketiga adalah parameter-parameter operasi penggasifikasian seperti besar kecilnya volume udara masuk, tekanan, jarak antara lubang masuk dan keluar atau panjang zona gasifikasi, temperatur dll.

Wieber \& Sikri, 1978 , mengungkapkan bahwa dari sekian banyak faktor-faktor yang dapat mempengaruhi jalannya proses gasifikasi, salah satu faktor yang perlu diperhatikan adalah zona gasifikasi batubara yang terbentuk atau dibentuk selama proses berlangsung.

Dalam kaitannya untuk menentukan pengaruh dari panjang zona gasifikasi terhadap proses gasifikasi batubara tersebut maka penelitian gasifikasi batubara yang dilakukan di Puslit Geoteknologi LIPI dilakukan dan untuk tujuan tersebut maka dua buah reaktor simulasi yang berbeda panjangnya telah dibuat. Reaktor simulasi yang dibuat diusahakan agar mampu merangkum parameter-parameter gasifikasi yang utama sehingga diharapkan bahwa proses gasifikasi yang terjadi dalam reaktor akan serupa dan atau mendekati proses penggasifikasian yang terjadi dialam (Thorness, G.B.,dkk., 1978). Dari hasil percobaan ini diharapkan pengaruh perbedaan panjang zone pembakaran atau gasifikasi terhadap hasil proses dapat diidentifikasi dan dimanfaatkan untuk peningkatan proses agar aplikasi proses gasifikasi batubara bawah tanah untuk skala lebih besar dikemudian hari dapat berjalan baik.

\section{PERALATAN DAN MATERIAL}

\section{Reaktor simulasi}

Untuk percobaan gasifikasi batubara bawah tanah pada skala laboratorium digunakan dua reaktor simulasi yang berbentuk silindris. Kedua reaktor simulasi terbuat dari plat besi dengan ketebalan $2 \mathrm{~mm}$. Reaktor pertama berukuran panjang $80 \mathrm{~cm}$ dengan diameter $30 \mathrm{~cm}$. Reaktor kedua berukuran panjang $200 \mathrm{~cm}$ dan diameter 30 
cm Kedua reaktor dilengkapi dengan lubang pembakaran awal, lubang udara masuk, lubang gas keluar.

Untuk reaktor pertama ada 2 buah lubang tempat pemasangan thermocouple. Thermokouple yang dipasang adalah thermokouple buatan SIKA, Jerman, yang mempunyai kemampuan mengukur temperatur sampai $1200^{\circ} \mathrm{C}$. Pemasangan thermokouple pertama adalah pada jarak $25 \mathrm{~cm}$ dari ujung reaktor dan yang kedua berjarak $25 \mathrm{~cm}$ setelah thermokouple pertama. Pada reaktor kedua; penempatan thermokouple pertama pada jarak $25 \mathrm{~cm}$ dari ujung reaktor; thermokouple kedua dan ketiga terletak pada jarak $25 \mathrm{~cm}$ setelahnya sedangkan thermokouple keempat berjarak $50 \mathrm{~cm}$ setelah thermokouple ketiga dan thermokouple kelima berjarak $50 \mathrm{~cm}$ dari thermopouple keempat. Jadi pada reaktor kedua terdapat 5 buah tempat buah lubang tempat pemasangan thermocouple.

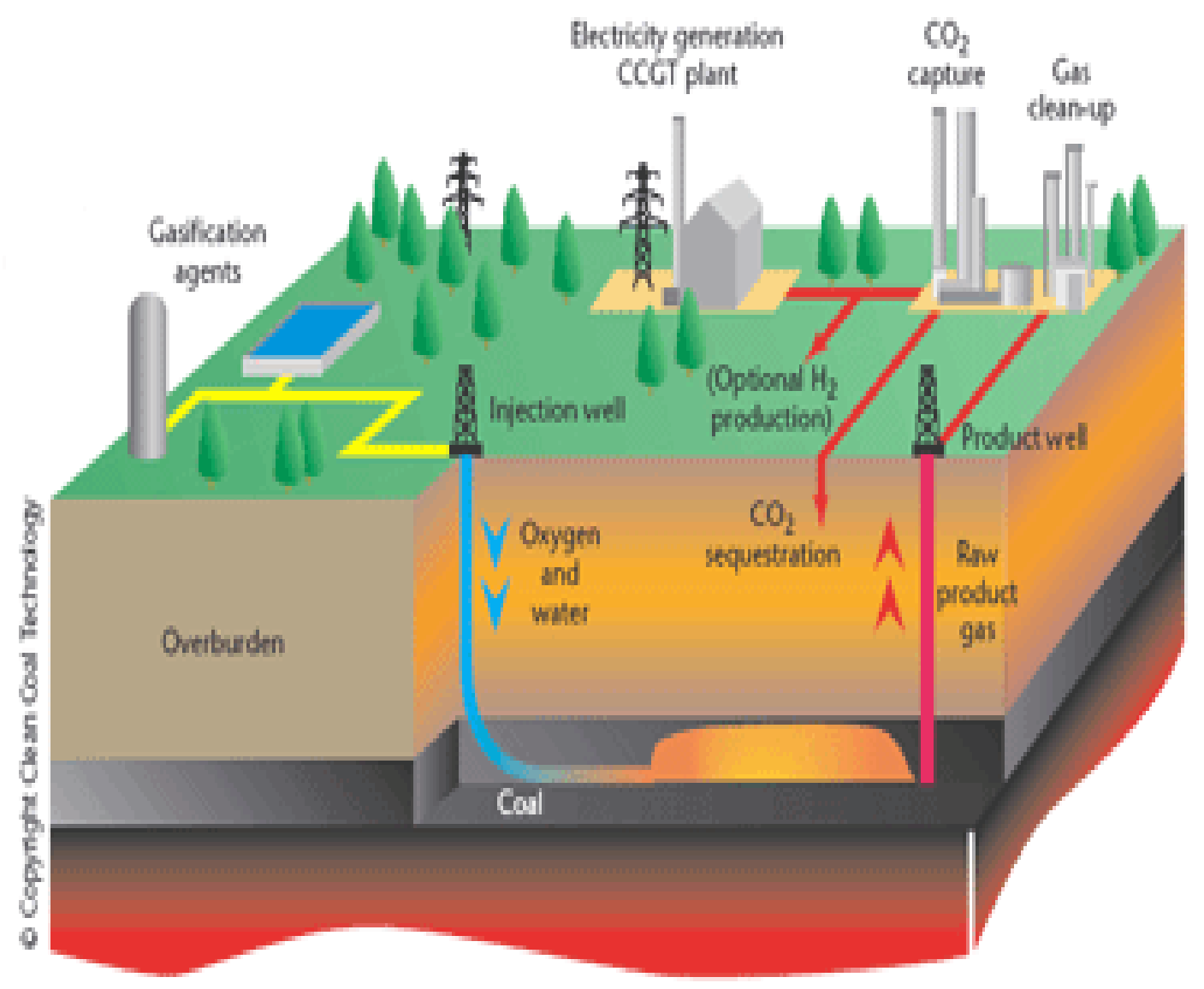

Gambar 1: Diagram gasifikasi batubara bawah tanah untuk pembangkit tenaga listrik. (World Coal Institute, 2005, WCI report: Clean Coal - Building a Future through Technology) 


\section{Kondisi percobaan}

Percobaan gasifikasi batubara bawah tanah skala laboratorium dilakukan dengan kondisi percobaan sebagai berikut:

- Waktu gasifikasi adalah 24 jam dimana 2 jam pertama dilakukan pembakaran awal dengan menggunakan alat pembakar/burner. Setelah batubara didalam reaktor mulai membara, burner dimatikan dan udara dari kompresor ditiupkan kedalam reaktor dengan volum yang ditentukan.

- Jumlah udara masuk yang ditiupkan kedalam reaktor adalah rata-rata sebesar: 70 liter/menit. Volum udara masuk diukur dengan alat gas meter yang dipinjam dari Perusahaan Gas Negara

\section{Pengambilan conto gas}

Gas hasil proses gasifikasi diambil dengan menampung gas yang dihasilkan dari proses dengan menggunakan tabung sampling gas yang terbuat dari kaca dengan panjang $30 \mathrm{~cm}$ dan diameter $5 \mathrm{~cm}$ yang dilengkapi dengan dua keran. Pengambilan conto gas dilakukan dengan cara gravitasi dimana gas yang dihasilkan dari reaktor ditarik masuk kedalam tabung sampling gas.

Cara penarikan gas adalah: Tabung sampling diisi air sampai penuh. Keran ditutup

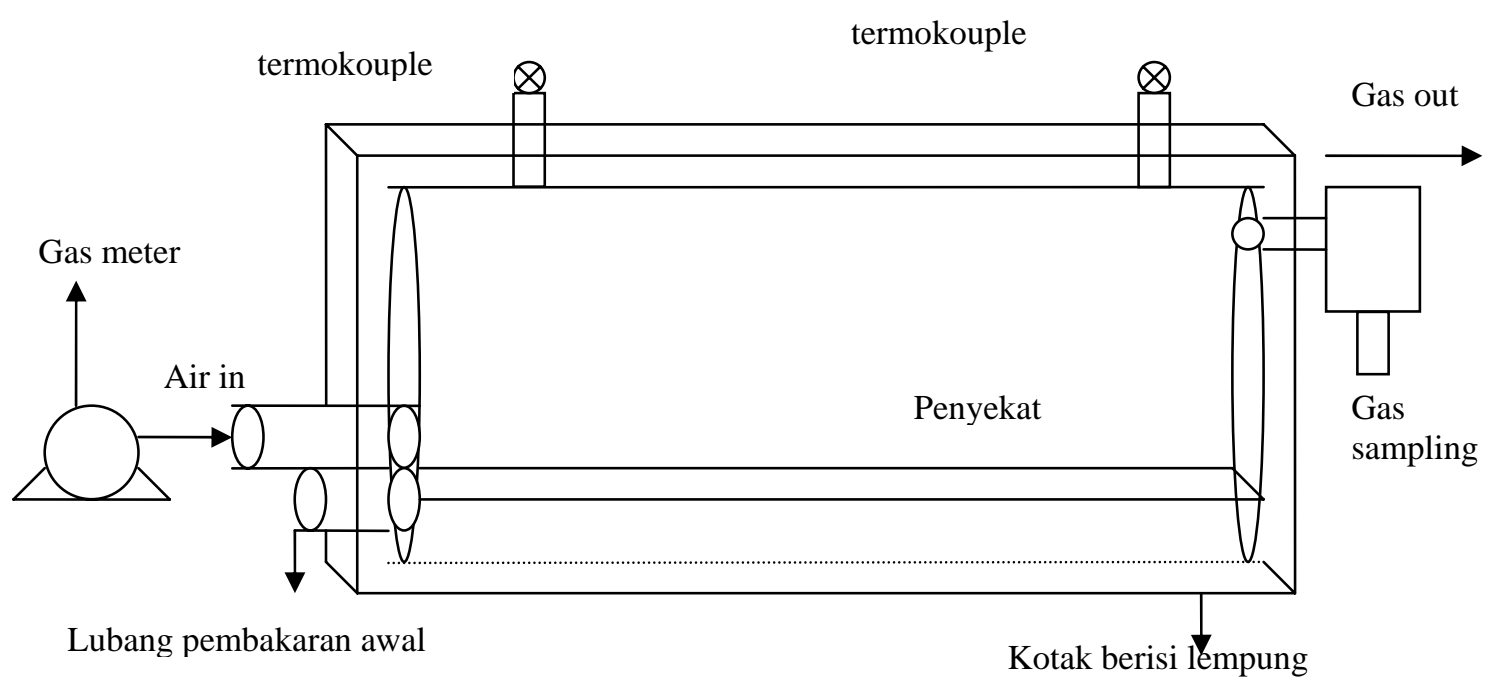

sehingga air tidak keluar. Keran pertama dihubungkan dengan lubang pengeluaran gas dari reaktor. Kedua keran dibuka secara bersamaan dengan pembukaan keran disesuaikan dengan kecepatan gas masuk. Air yang mengalir keluar dari tabung akan menarik gas dari reaktor dan memasuki tabung. Setelah tabung terisi penuh dengan gas produk gasifikasi maka kedua keran ditutup secara bersamaan dan kemudian tabung yang berisi gas siap dikirim untuk dianalisa.

Pengambilan conto gas dilakukan setiap jam.

\section{Analisa gas}

Analisa gas hasil proses gasifikasi dilakukan dengan menggunakan alat Orsat yang dilakukan di Perusahaan Gas Negara. Komponen gas yang dianalisa adalah: $\mathrm{CO}_{2}$; $\mathrm{C}_{\mathrm{n}} \mathrm{H}_{\mathrm{m}} ; \mathrm{O}_{2} ; \mathrm{CO} ; \mathrm{H}_{2}: \mathrm{C}_{3} \mathrm{H}_{8} ; \mathrm{CH}_{4}$ dan $\mathrm{N}_{2}$, Nilai kalori gas dihitung berdasarkan prosen kandungan gas $\mathrm{C}_{n} \mathrm{H}_{m}$; $\mathrm{CO} ; \mathrm{H}_{2}: \mathrm{C}_{3} \mathrm{H}_{8}$ dan $\mathrm{CH}_{4}$.

Skema percobaan secara sederhana dapat dilihat pada Gambar 2 berikut ini.

Gambar 2: Skema percobaan gasifikasi batubara bawah tanah skala laboratorium (disederhanakan). 


\section{HASIL PERCOBAAN DAN PEMBAHASAN}

Hasil percobaan gasifikasi batubara dengan menggunakan reaktor pertama dicantumkan pada Tabel 1 sedangkan hasil percobaan dengan menggunakn reaktor kedua dapat dilihat pada Tabel 2.

Tabel 1. Hasil percobaan gasifikasi batubara bawah tanah skala laboratorium dengan menggunakan reaktor pertama

\begin{tabular}{|c|c|c|c|c|c|c|c|c|c|c|c|c|}
\hline \multirow[b]{2}{*}{ no } & \multicolumn{8}{|c|}{ Komposisi gas hasil (\% ) } & \multirow{2}{*}{$\begin{array}{l}\text { Nilai kalori } \\
\mathrm{Kcal} / \mathrm{m}^{3}\end{array}$} & \multirow{2}{*}{ Volume udara masuk 1/m } & \multirow{2}{*}{$\begin{array}{l}\mathrm{T} 1 \\
{ }^{\circ} \mathrm{C}\end{array}$} & \multirow{2}{*}{$\begin{array}{l}\mathrm{T} 2 \\
{ }^{\circ} \mathrm{C}\end{array}$} \\
\hline & $\mathrm{CO}_{2}$ & $\mathrm{C}_{\mathrm{n}} \mathrm{H}_{\mathrm{m}}$ & $\mathrm{O}_{2}$ & $\mathrm{CO}$ & $\mathrm{H}_{2}$ & $\mathrm{C}_{3} \mathrm{H}_{8}$ & $\mathrm{CH}_{4}$ & $\mathrm{~N}_{2}$ & & & & \\
\hline 1 & 13,8 & 0,0 & 4,4 & 1,4 & 1,8 & 0,6 & 0,4 & 77,6 & 263 & 70 & 345 & 100 \\
\hline 2 & 14,0 & 0,2 & 4,2 & 1,2 & 2,4 & 0,6 & 1,8 & 75,6 & 400 & 70 & 425 & 125 \\
\hline 3 & 13,2 & 0,0 & 6,2 & 1,4 & 2,8 & 0,4 & 2,0 & 74,0 & 391 & 70 & 550 & 150 \\
\hline 4 & 14,1 & 0,2 & 4,1 & 1,8 & 1,9 & 0,5 & 2,4 & 75,0 & 435 & 70 & 600 & 160 \\
\hline 5 & 11,7 & 0,1 & 7,2 & 1,6 & 2,0 & 0,4 & 2,0 & 75,0 & 373 & 70 & 620 & 190 \\
\hline 6 & 11,8 & 0,2 & 6,0 & 1,8 & 3,0 & 0,5 & 1,7 & 75,0 & 403 & 70 & 645 & 205 \\
\hline 7 & 12,0 & 0,0 & 6,0 & 2,7 & 2,3 & 0,8 & 1,6 & 74,6 & 467 & 70 & 670 & 270 \\
\hline 8 & 11,8 & 0,0 & 6,4 & 2,6 & 1,8 & 0,2 & 2,2 & 75,0 & 369 & 70 & 685 & 310 \\
\hline 9 & 11,6 & 0,2 & 6,0 & 3,8 & 1,8 & 0,4 & 3,0 & 74,2 & 492 & 70 & 705 & 380 \\
\hline 10 & 12,8 & 0,2 & 5,0 & 3,0 & 3,2 & 0,4 & 2,4 & 73,0 & 484 & 70 & 680 & 425 \\
\hline 11 & 13,4 & 0,4 & 3,6 & 3,0 & 2,6 & 0,8 & 1,8 & 74,4 & 502 & 70 & 675 & 480 \\
\hline 12 & 14,4 & 0,0 & 3,2 & 3,4 & 3,0 & 0,6 & 2,2 & 73,2 & 517 & 70 & 670 & 515 \\
\hline 13 & 13,8 & 0,2 & 3,2 & 3,4 & 1,9 & 0,9 & 1,6 & 75,0 & 498 & 70 & 660 & 530 \\
\hline 14 & 13,6 & 0,0 & 4,0 & 3,4 & 1,6 & 0,2 & 1,2 & 76,0 & 296 & 70 & 655 & 550 \\
\hline 15 & 13,2 & 0,0 & 4,0 & 3,4 & 1,0 & 0,2 & 0,6 & 77,6 & 225 & 70 & 655 & 570 \\
\hline 16 & 14,2 & 0,2 & 3,2 & 2,8 & 2,0 & 0,1 & 0,5 & 77,0 & 217 & 70 & 650 & 585 \\
\hline 17 & 13,6 & 0,0 & 4,0 & 3,2 & 1,2 & 0,0 & 0,8 & 77,2 & 198 & 70 & 650 & 610 \\
\hline 18 & 11,6 & 0,0 & 3,0 & 3,0 & 1,0 & 0,0 & 0,2 & 81,2 & 133 & 70 & 650 & 620 \\
\hline 19 & 13,4 & 0,0 & 4,4 & 3,0 & 1,2 & 0,0 & 0,4 & 77,6 & 156 & 70 & 650 & 630 \\
\hline 20 & 13,6 & 0,0 & 4,2 & 3,2 & 0,8 & 0,0 & 0,4 & 77,8 & 151 & 70 & 625 & 635 \\
\hline 21 & 12,2 & 0,0 & 4,8 & 3,0 & 1,0 & 0,0 & 0,2 & 77,8 & 133 & 70 & 620 & 645 \\
\hline 22 & 12,8 & 0,0 & 5,2 & 3,0 & 0,8 & 0,0 & 0,2 & 78,0 & 127 & 70 & 610 & 650 \\
\hline 23 & 13,2 & 0,0 & 4,4 & 3,0 & 1,0 & 0,0 & 0,4 & 78,4 & 151 & 70 & 595 & 630 \\
\hline 24 & 13,8 & 0,0 & 4,0 & 2,8 & 2,0 & 0,0 & 0,2 & 77,2 & 156 & 70 & 550 & 620 \\
\hline
\end{tabular}

Perincian dari fluktuasi kandungan gas dari proses gasifikasi batubara diuraikan pada Gambar 3; 4; 5; 6; dan 7. Gambar-gambar tersebut memperlihatkan fluktuasi dari kandungan gas $\mathrm{CO}_{2} ; \mathrm{CO} ; \mathrm{H}_{2}$; dan $\mathrm{CH}_{4}$ yang diperoleh dari setiap percobaan gasifikasi batubara dengan menggunakan reaktor pertama dan kedua.

Berdasarkan Gambar 3 diatas proses gasifikasi batubara pada reaktor pertama menghasilkan pembentukan gas $\mathrm{CO}_{2}$ yang lebih banyak dibandingkan dengan proses pada reaktor kedua. Gambar 4 memperlihatkan bahwa pembentukan gas CO pada reaktor pertama juga melebihi pembentukan gas CO pada reaktor kedua, meskipun perbedaan jumlah gas CO yang terbentuk tidak terlalu besar. Demikian pula pembentukan gas $\mathrm{H}_{2}$ dari reaktor pertama sedikit lebih banyak dibandingkan dengan gas $\mathrm{H}_{2}$ yang dihasilkan dari reaktor kedua (lihat Gambar 5). Demikian pula Gambar 6 memperlihatkan bahwa jumlah gas $\mathrm{CH}_{4}$ yang dihasilkan reaktor pertama relatip jumlahnya 
melebihi gas $\mathrm{CH}_{4}$ yang dihasilkan dari reaktor kedua. Berdasarkan pembentukan gas-gas $\mathrm{CO}_{2} ; \mathrm{CO} ; \mathrm{H}_{2}$ dan $\mathrm{CH}_{4}$ tersebut, maka dapat dikatakan bahwa reaksi gasifikasi pada reaktor pertama berjalan lebih lancar dibandingkan dengan reaksi gasifikasi pada reaktor kedua.

Tabel 2. Hasil percobaan gasifikasi batubara bawah tanah skala laboratorium dengan menggunakan reaktor kedua

\begin{tabular}{|c|c|c|c|c|c|c|c|c|c|c|c|c|c|c|c|}
\hline \multirow[t]{2}{*}{ no } & \multicolumn{8}{|c|}{ Komposisi gas hasil (\% ) } & \multirow{2}{*}{$\begin{array}{c}\text { Nilai kalori } \\
\text { Kcal } / \mathrm{m}^{3}\end{array}$} & \multirow{2}{*}{$\begin{array}{l}\text { Vol } \\
\text { Ud. } \\
\text { l/m }\end{array}$} & \multirow{2}{*}{$\begin{array}{l}\mathrm{T} 1 \\
{ }^{\circ} \mathrm{C}\end{array}$} & \multirow{2}{*}{$\begin{array}{l}\mathrm{T} 2 \\
{ }^{\circ} \mathrm{C} \\
\end{array}$} & \multirow{2}{*}{$\begin{array}{l}\mathrm{T} 3 \\
{ }^{\circ} \mathrm{C} \\
\end{array}$} & \multirow{2}{*}{$\begin{array}{l}\mathrm{T} 4 \\
{ }^{\circ} \mathrm{C} \\
\end{array}$} & \multirow{2}{*}{$\begin{array}{l}\mathrm{T} 5 \\
{ }^{\circ} \mathrm{C} \\
\end{array}$} \\
\hline & $\mathrm{CO}_{2}$ & $\mathrm{C}_{n} \mathrm{H}_{\mathrm{n}}$ & $\mathrm{O}_{2}$ & $\mathrm{CO}$ & $\mathrm{H}_{2}$ & $\mathrm{C}_{3} \mathrm{H}_{8}$ & $\mathrm{CH}_{4}$ & $\mathrm{~N}_{2}$ & & & & & & & \\
\hline 1 & 5,0 & 0,2 & 13,0 & 2,0 & 2,0 & 0,6 & 0,6 & 76,6 & 304 & 70 & 470 & 310 & 70 & 55 & 40 \\
\hline 2 & 15,0 & 0,3 & 4,0 & 2,0 & 4,0 & 0,8 & 1,2 & 72,7 & 460 & 70 & 925 & 850 & 200 & 125 & 50 \\
\hline 3 & 14,0 & 0,1 & 4,0 & 1,8 & 1,4 & 0,4 & 1,4 & 76,9 & 308 & 70 & 905 & 895 & 240 & 245 & 85 \\
\hline 4 & 10,6 & 0,0 & 8,2 & 1,8 & 2,0 & 0,2 & 1,0 & 76,2 & 244 & 70 & 880 & 935 & 245 & 280 & 120 \\
\hline 5 & 9,0 & 0,0 & 9,0 & 2,8 & 2,4 & 0,0 & 0,8 & 76,0 & 221 & 70 & 790 & 840 & 220 & 255 & 135 \\
\hline 6 & 6,4 & 0,0 & 12,4 & 2,8 & 1,2 & 0,2 & 1,0 & 76,0 & 250 & 70 & 680 & 825 & 185 & 220 & 130 \\
\hline 7 & 7,4 & 0,0 & 9,6 & 2,0 & 1,9 & 0,1 & 0,3 & 78,7 & 162 & 70 & 610 & 805 & 170 & 205 & 135 \\
\hline 8 & 7,4 & 0,0 & 9,8 & 4,0 & 1,0 & 0,0 & 0,6 & 77,2 & 197 & 70 & 565 & 735 & 165 & 187 & 135 \\
\hline 9 & 7,4 & 0,0 & 10,4 & 2,4 & 0,8 & 0,1 & 1,5 & 76,2 & 249 & 70 & 535 & 725 & 155 & 185 & 135 \\
\hline 10 & 6,4 & 0,0 & 12,2 & 2,2 & 0,8 & 0,0 & 0,8 & 77,6 & 158 & 70 & 495 & 705 & 150 & 185 & 150 \\
\hline 11 & 7,8 & 0,0 & 11,0 & 2,8 & 0,6 & 0,0 & 1,0 & 76,8 & 187 & 70 & 485 & 670 & 150 & 185 & 165 \\
\hline 12 & 7,0 & 0,1 & 10,9 & 2,5 & 1,0 & 0,4 & 0,6 & 77,5 & 244 & 70 & 450 & 650 & 150 & 180 & 180 \\
\hline 13 & 8,0 & 0,0 & 9,6 & 3,2 & 1,0 & 0,2 & 1,0 & 77,2 & 255 & 70 & 430 & 630 & 140 & 175 & 200 \\
\hline 14 & 7,8 & 0,0 & 10,4 & 2,8 & 1,3 & 0,1 & 1,7 & 77,6 & 293 & 70 & 405 & 600 & 135 & 175 & 225 \\
\hline 15 & 8,4 & 0,1 & 9,6 & 2,9 & 1,6 & 1,2 & 0,2 & 76,0 & 416 & 70 & 390 & 590 & 135 & 175 & 240 \\
\hline 16 & 4,2 & 0,0 & 13,8 & 1,8 & 2,0 & 0,0 & 0,1 & 78,1 & 118 & 70 & 390 & 580 & 120 & 175 & 245 \\
\hline 17 & 7,8 & 0,0 & 11,4 & 2,4 & 0,8 & 0,2 & 0,1 & 77,3 & 138 & 70 & 385 & 555 & 140 & 170 & 245 \\
\hline 18 & 7,8 & 0,0 & 9,6 & 3,2 & 2,6 & 0,1 & 1,2 & 75,5 & 297 & 70 & 350 & 535 & 130 & 170 & 245 \\
\hline 19 & 9,4 & 0,1 & 8,2 & 3,4 & 2,2 & 0,2 & 1,2 & 75,4 & 314 & 70 & 325 & 510 & 125 & 165 & 235 \\
\hline 20 & 9,2 & 0,0 & 8,2 & 3,2 & 1,2 & 0,2 & 0,8 & 77,0 & 243 & 70 & 315 & 480 & 125 & 165 & 235 \\
\hline 21 & 9,2 & 0,0 & 9,0 & 3,0 & 2,0 & 0,2 & 1,0 & 73,5 & 278 & 70 & 310 & 465 & 120 & 165 & 230 \\
\hline 22 & 8,0 & 0,0 & 10,1 & 2,9 & 0,6 & 0,2 & 0,8 & 77,4 & 217 & 70 & 305 & 455 & 120 & 165 & 230 \\
\hline 23 & 7,8 & 0,0 & 10,4 & 3,0 & 0,6 & 0,2 & 1,0 & 77,0 & 237 & 70 & 290 & 425 & 120 & 160 & 220 \\
\hline 24 & 8,4 & 0,0 & 10,2 & 2,8 & 0,6 & 0,2 & 0,8 & 76,2 & 214 & 70 & 280 & 410 & 115 & 150 & 215 \\
\hline
\end{tabular}

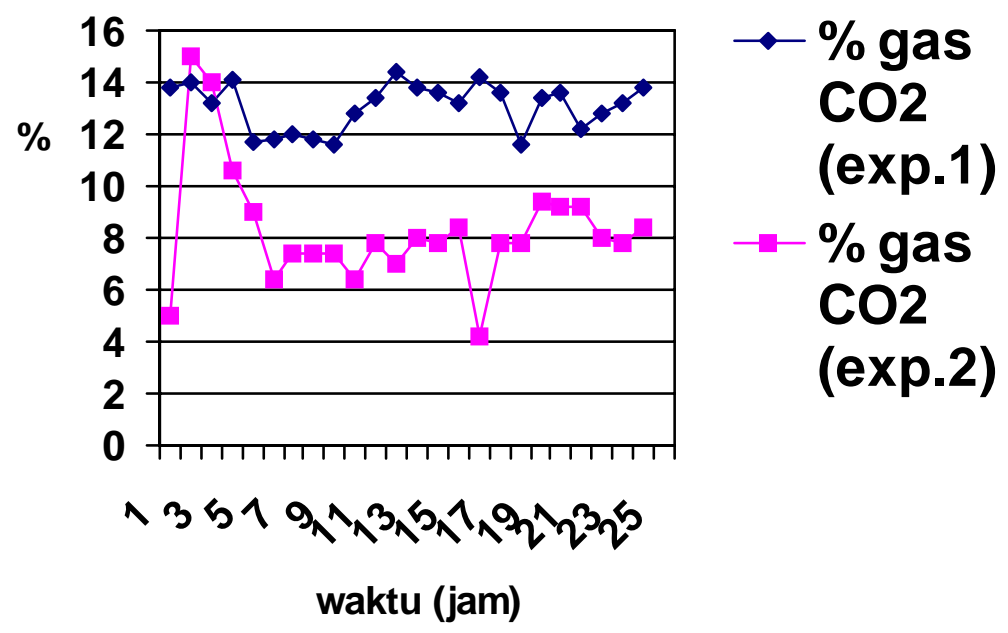

Gambar 3: Perubahan kandungan gas $\mathrm{CO}_{2}$ dari proses gasifikasi batubara 


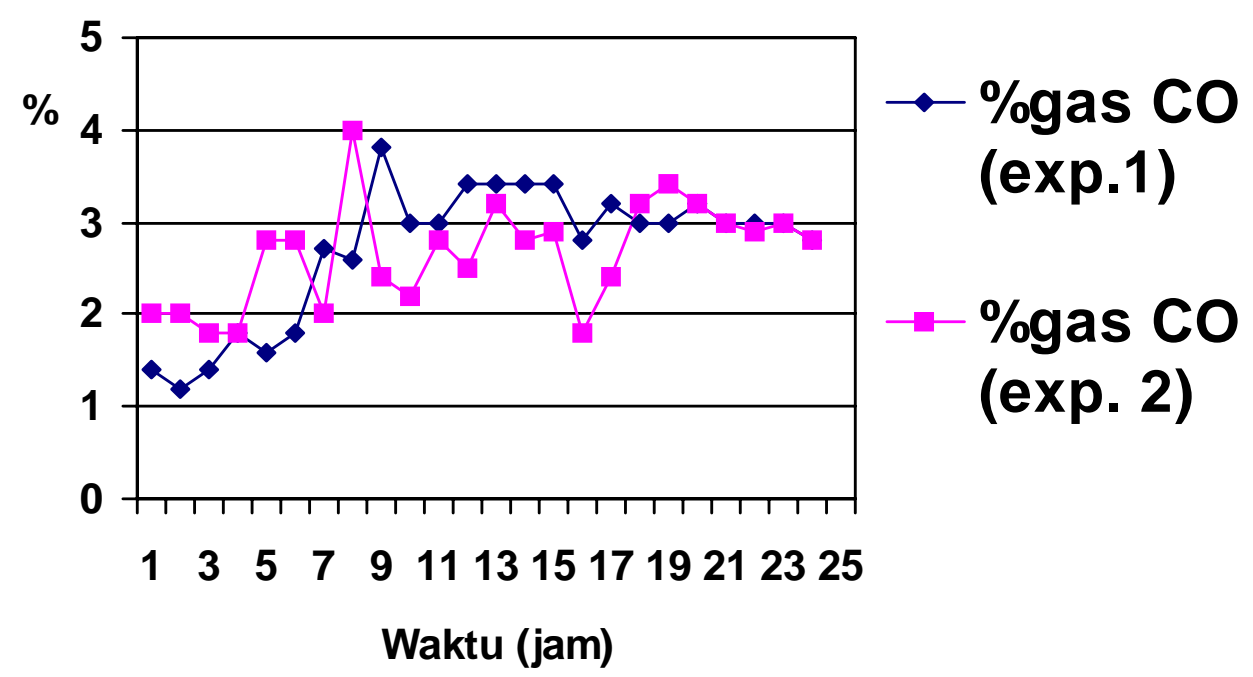

Gambar 4: Perubahan kandungan gas CO dari proses gasifikasi batubara

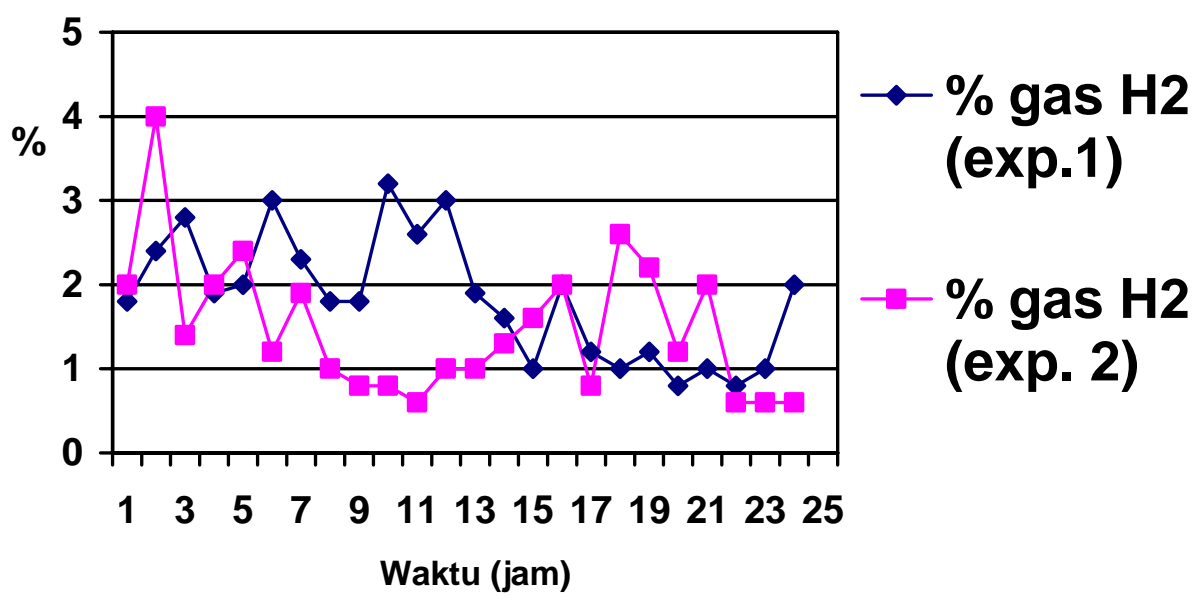

Gambar 5. Perubahan kandungan gas $\mathbf{H}_{2}$ dari proses gasifikasi batubara 


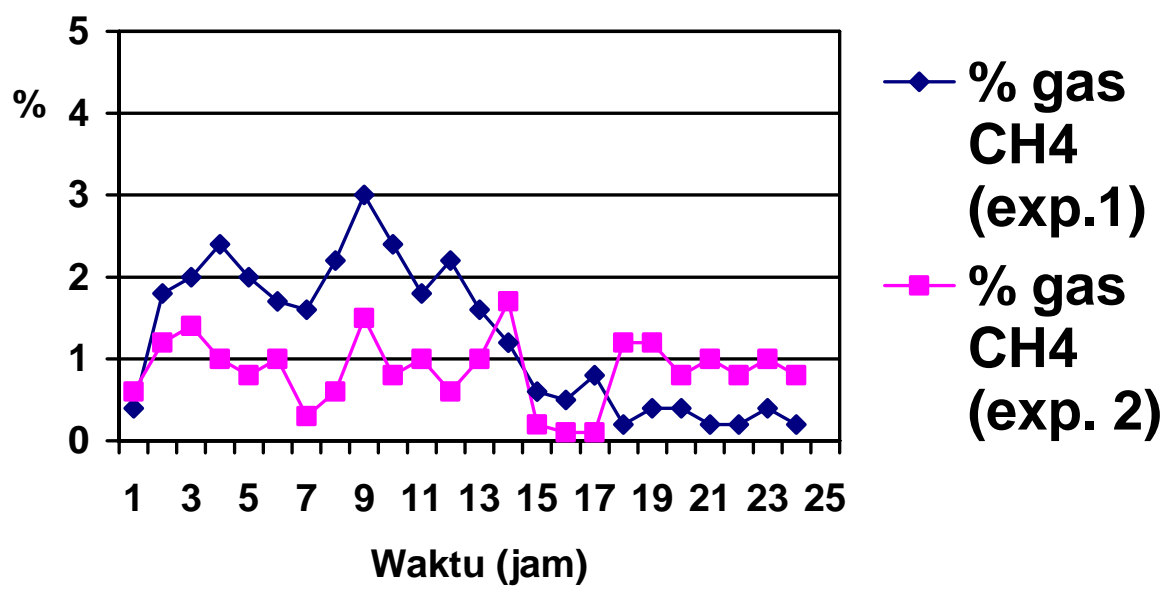

Gambar 6. Perubahan kandungan gas $\mathrm{CH}_{4}$ dari proses gasifikasi batubara

Hal tersebut didukung pula oleh nilai kalori gas hasil gasifikasi dari masing-masing reaktor seperti yang terlihat pada Gambar 7.

Fluktuasi nila i kalori gas yang dihasilkan dari eksperimen 1 (menggunakan reaktor pertama) mempunyai nilai kalori yang lebih tinggi dibandingkan nilai kalori gas hasil dari reaktor kedua.

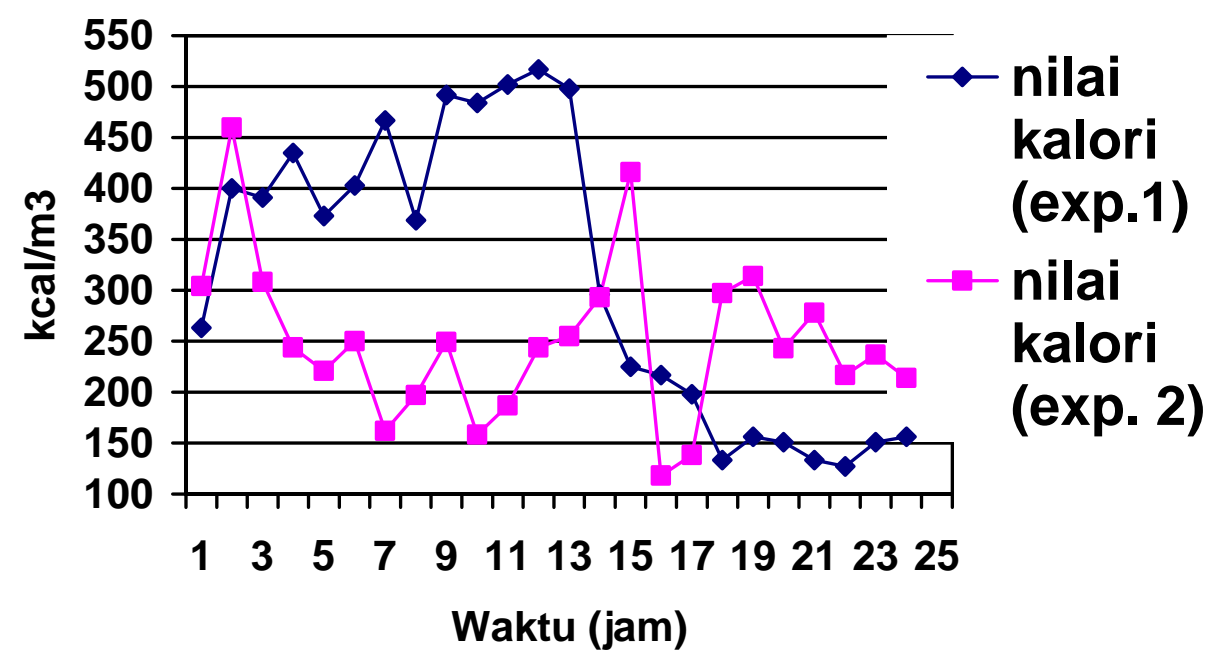

Gambar 7. Perubahan nilai kalori gas dari proses gasifikasi batubara 
Data temperatur percobaan dari masingmasing reaktor juga menunjukkan bahwa reaksi yang terjadi dalam kedua reaktor berjalan dengan kemampuan yang berbeda. Gambar 8 memperlihatkan bahwa temperatur reaksi yang terjadi selama proses gasifikasi ternyata mempunyai pola berbeda untuk setiap percobaan. Pola temperatur yang teramati pada reaktor pertama berjalan dengan pola yang berbeda dengan pola temperatur percobaan pada reaktor kedua. Pada reaktor pertama reaksi berjalan dengan awal yang rendah, kemudian terus meningkat pada sampai jam ke 10 untuk T1 sedangkan untuk T2 temperatur terus meningkat sampai jam ke 22. Pada percobaan dengan menggunakan reaktor pertama temperatur gasifikasi yang dicapai lebih tinggi dibandingkan dengan temperatur yang dicapai pada reaktor kedua (khususnya setelah percobaan berjalan diatas 10 jam). Dilain pihak pola temperatur pada reaktor kedua menunjukkan kondisi yang lain yaitu mengalami peningkatan yang sangat tinggi untuk T1 sampai jam ke 2, lalu terus menurun, sedangkan untuk T2 meningkat sampai jam ke 5 lalu terus menurun. Perbedaan pola temperatur T1 dan T2 pada kedua reaktor tersebut dapat mewakili kondisi yang terjadi.

Secara mendasar proses gasifikasi merupakan suatu konversi dari batubara padat menjadi gas yang meliputi berbagai tahapan yaitu pertama batubara mengalami proses pengeringan, diikuti dengan reaksi devolatisasi, pirolisa dan diikuti oleh proses gasifikasi. Dalam kondisi tersebut berbagai faktor-faktor disekitarnya akan mempengaruhi reaksi-reaksi yang terjadi selama proses gasifikasi berlangsung. Reaksi-reaksi kimia yang terjadi berkaitan erat dengan proses fisika yang terjadi secara simultan dan pembentukan gas-gas hasil (Probstein \& Hicks, 1982).

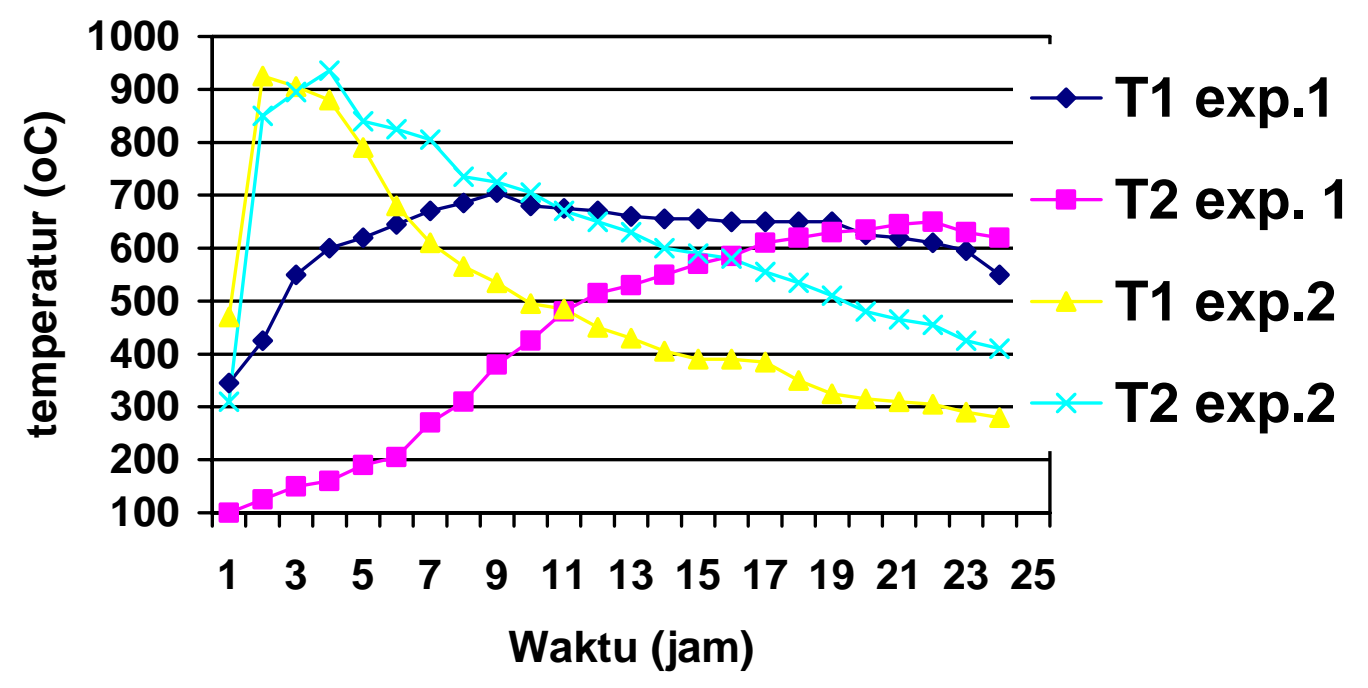

Gambar 8. Temperatur percobaan $\mathrm{T} 1$ dan $\mathrm{T} 2$ dari proses gasifikasi batubara 
Beberapa reaksi kimia yang penting dalam proses gasifikasi adalah sebagai berikut:

$$
\begin{aligned}
& \text { 1. } \mathrm{H}_{2}+\mathrm{C} \rightarrow \mathrm{H}_{2}+\mathrm{CO} \\
& \text { 2. } \mathrm{CO}_{2}+\mathrm{C} \leftrightarrow 2 \mathrm{CO} \\
& \text { 3. } 2 \mathrm{H}_{2}+\mathrm{C} \rightarrow \mathrm{CH}_{4} \\
& \text { 4. } \mathrm{H}_{2} \mathrm{O}+\mathrm{CO} \leftrightarrow \mathrm{H}_{2}+\mathrm{CO}_{2} \\
& \text { 5. } 3 \mathrm{H}_{2}+\mathrm{CO} \leftrightarrow \mathrm{CH}_{4}+\mathrm{H}_{2} \mathrm{O}
\end{aligned}
$$

Secara umum proses gasifikasi batubara diawali dengan pembakaran batubara tersebut yang kemudian akan menghasilkan pemanasan berikutnya. Pada waktu pembakaran tersebut, temperatur akan naik dengan cepat karena pembakaran karbon dengan oksigen merupakan reaksi yang eksotermik sehingga temperatur dalam zona gasifikasi meningkat dengan cepat. Temperatur tinggi yang dihasilkan akan menyediakan sejumlah kalori pendorong yang dipergunakan pada pelaksanaan reaksi antara arang batubara/char dan uap air yang terlebih lanjut mempengaruhi hasil reaksi seperti yang diperlihatkan oleh komposisi gas hasil. Reaksi no 1, 2 dan 3 mempunyai akibat yang langsung berkaitan dengan tahap perubahan dari char ke produk gas yang dihasilkannya sedangkan reaksi no 4 dan 5 berakibat pada komposisi gas produk. Young (1977) menyebutkan bahwa pembentukan gas produk pada suatu proses gasifikasi mempunyai kaitan erat dengan prosedur dekomposisi batubara dan prosedur dari reaksi-reaksi yang terjadi. Berdasarkan seri reaksi kimia yang diperlihatkan kelima reaksi tersebut maka aktifitas reaksi gasifikasi secara umum mengarah pada pembentukan gas $\mathrm{CO}_{2} ; \mathrm{CO}$; $\mathrm{H}_{2}$; dan $\mathrm{CH}_{4}$.

Selain itu jenis oksidan yang diitupkan masuk kedalam sistim proses gasifikasi juga berpengaruh terhadap hasil proses. Pada pelaksanaan eksperimen dengan reaktor simulasi dalam studi ini, oksidan yang ditiupkan masuk adalah udara. Udara yang dihasilkan dari kompresor ditiupkan kedalam reaktor (pertama dan kedua) dan diatur pada kecepatan serta jumlah yang sama.

Littlewood (1977) menyebutkan bahwa gas produksi yang dihasilkan dari proses gasifikasi sebagian besar merupakan hasil pembakaran partial dari karbon yang terdapat pada batubara dengan udara dan penggunaan udara saja tanpa adanya penambahan oksigen menyebabkan reaksi antara karbon dan oksigen berjalan kurang baik. Sebagai akibatnya maka proses gasifikasi hanya menghasilkan gas yang mempunyai nilai kalori rendah. Untuk menghasilkan produk gas mempunyai nilai kalori yang lebih baik disarankan agar udara masuk dicampur dengan uap air atau ada penambahan oksigen (Skafa, 1960).

Jumlah udara yang mengalir masuk kedalam reaktor dan melalui lapisan batubara yang terdapat didalamnya juga mempengaruhi reaksi-reaksi kimia yang terjadi. Pada reaktor pertama jumlah batubara yang terdapat didalam reaktor lebih sedikit jumlahnya dibandingkan dengan jumlah batubara yang terdapat didalam reaktor kedua. Masa batubara yang terdapat didalam reaktor dapat dianalogkan dengan panjang lapisan batubara itu sendiri sehingga reaksi yang berlangsung juga dapat dikatakan tergantung pada panjang lapisan batubara. Panjang reaktor pertama adalah $80 \mathrm{~cm}$ sedangkan panjang reaktor kedua adalah $200 \mathrm{~cm}$, yang berarti panjang reaktor kedua adalah 2,5 kali lipat dari reaktor pertama. Dalam hal ini jumlah aliran udara masuk sebesar 70 liter/menit bagi reaktor pertama mampu memenuhi kebutuhan reaksi yang terjadi tetapi untuk reaktor kedua dengan panjang zona yang lebih jauh, jumlah udara masuk sebesar 70 liter/menit tidak mencukupi sehingga sebagai akibatnya kualitas gas hasil yang dihasilkannya berbeda.

Meskipun demikian perlu disadari bahwa masih banyak faktor-faktor lainnya yang perlu diperhatikan seperti misalnya lokasi awal penyalaan; alur gasifikasi yang sebaiknya diusahakan agar mulai terjadi dibagian bawah lapisan batubara; permeabilitas lapisan batubara, jenis batubara; kondisi devolatilisasi batubara; reaktifitas dll. (Gunn, 1978). 


\section{KESIMPULAN DAN SARAN}

Percobaan gasifikasi batubara dengan menggunakan dua buah reaktor yang berbeda panjangnya menghasilkan data-data yang menunjukkan bahwa panjang zona gasifikasi didalam reaktor menyebabkan proses gasifikasi berjalan pada kondisi dan pola yang tidak sama. Hal tersebut menyebabkan terjadinya perbedaan dari komposisi gas produk seperti yang dinyatakan dengan prosentase kandungan gas-gas $\mathrm{CO}_{2} ; \mathrm{CO} ; \mathrm{H}_{2}$ dan $\mathrm{CH}_{4}$. Selain itu, fluktuasi nilai kalori gas yang dihasilkan dari reaktor pertama mempunyai nilai kalori yang lebih tinggi dibandingkan nilai kalori gas hasil dari reaktor kedua. Hal ini dapat diinterpretasikan bahwa reaksi gasifikasi batubara pada reaktor kedua tidak berjalan sebaik reaksi gasifikasi pada reaktor pertama.

Data temperatur percobaan dari masingmasing reaktor juga menunjukkan bahwa reaksi yang terjadi dalam kedua reaktor berjalan dengan kemampuan yang berbeda. Pada percobaan dengan menggunakan reaktor pertama temperatur gasifikasi yang dicapai lebih tinggi dibandingkan dengan temperatur yang dicapai pada reaktor kedua (khususnya setelah percobaan berjalan 10 jam). Temperatur tinggi yang dihasilkan akan menyediakan sejumlah kalori pendorong yang dipergunakan pada pelaksanaan reaksi antara arang batubara/char dan uap air yang terlebih lanjut mempengaruhi hasil reaksi seperti yang diperlihatkan oleh gas hasil.

Berdasarkan evaluasi hasil percobaan tersebut dapat disarankan bahwa dalam suatu proses gasifikasi batubara bawah tanah adanya perubahan panjang zona gasifikasi memerlukan penyesuaian dalam berbagai faktor operasional gasifikasi, yaitu pertama: Udara yang digunakan mempengaruhi kualitas gas hasil dan agar produk gas mempunyai nilai kalori yang lebih baik disarankan agar dicampur dengan uap air atau ada penambahan oksigen (Skafa, 1960). Meskipun demikian perlu disadari bahwa masih banyak faktor-faktor lainnya yang perlu diperhatikan seperti misalnya lokasi awal penyalaan; alur gasifikasi yang sebaiknya diusahakan agar mulai terjadi dibagian bawah lapisan batubara; permeabilitas lapisan batubara, jenis batubara; kondisi devolatilisasi batubara; reaktifitas dll. (Gunn, 1978).

Kompleksnya proses gasifikasi batubara menyebabkan perlu adanya kelanjutan penelitian yang lebih terperinci.

\section{PUSTAKA}

Armitage,M., and Green, M.B., 2001, Underground Coal Gasification in the United Kingdom, $18^{\text {th }}$ International Pittsburgh Coal Conference, December 2001, Newcastle, Australia.

Edgar, T.F., 1974, The Potential of Insitu Coal Gaification in The South West United State. Paper Presented at Project Independence Hearings, Houston, Texas, Sept.18, 1974.

Green, M.B., Singleton, A., 2005, USG Comparison of European and US Technologies, 22nd Pittsburg Coal Conference, Pittsburg PA, September.

Gunn, R.D., et al, 1978, A Permeation Theory For Insitu Coal Gasification, Society of Petroleum Engineers Journal, October 1978, hal. 300-314.

Littlewood, K., 1977, Gasification Theory and Application, Progress Energy Combustion Science, vol. 3, hal. 35-71.

Probsteins, R.F., Hicks R.E., 1982, Synthetic Fuels, McGraw- Hill., Inc.,hal. 101.

Rudolph, P. F. H., 1977, The Lurgi Process For Coal Gasifcation, Energy Technology Handbook, McGraw-Hill Book Company, USA, hal. 1-190.

Skafa, P.V., 1960. Underground Gasification of Coal, UCRL-Trans-10880, Moscow.

Schreider L.A., Whieldon, C.E., 1977, Underground Coal Gasification, A Status Report, Journal of Petroleum Technology, vol. 29, hal. 1179-1185.

Thorness, G.B., et al., 1978, Insitu Coal Gasification, Model Calculation and Laboratory Experiments, Society of Petroleum Engineers Journal, April 
1978, hal. 105-116.

Wieber D.H., Sikri, A.P., 1978, The Development Of Insitu Process For Energy And Fuels From Coal, Mining Engineering, vol.,30, no. 5, p. 557-563.

World Coal Institute, 2005 WCI report: Clean Coal- Building a Future through Technology.

Young, J.E., et al, 1977, Kinetics of Char Gasification Reactions Under Conditions of Underground Coal
Gasification, Proceedings of The Third Annual Underground Coal Conversion Symposium, hal. 215-223. 